\title{
Desempenho Silvicultural e Produtivo de Eucalipto sob Diferentes Arranjos Espaciais em Sistema Agrossilvipastoril
}

\author{
Tadário Kamel de Oliveira(1), Renato Luiz Grisi Macedo(2), Nelson Venturin ${ }^{(2)}$ e Emílio Manabu Higashikawa(2) \\ (1) Embrapa Acre, BR 364, Km 14, Caixa Postal 321, CEP 69908-970, Rio Branco-AC. E-mail: tadario@cpafac.embrapa.br; (2) Universidade \\ Federal de Lavras (UFLA), CEP 37200-000, Lavras-MG. E-mails: rlgrisi@ufla.br; venturin@ufla.br; emilio.higashikawa@gmail.com
}

\begin{abstract}
Resumo - A produção de madeira de eucalipto para serraria está condicionada a longos ciclos de corte, maiores espaçamentos e tratos silviculturais específicos, e permite o consórcio com espécies produtoras de grãos e forragem. Objetivou-se avaliar e caracterizar a dinâmica de crescimento e produtividade de eucalipto, sob diferentes arranjos espaciais em sistema agrossilvipastoril. O experimento foi implantado em área de cerrado, com mudas clonais de um híbrido natural de Eucalyptus camaldulensis Dehnh com E. urophylla S.T. Blake, em consórcio com arroz no primeiro ano, soja no segundo e Brachiaria brizantha nos seguintes. O delineamento utilizado foi o de blocos casualizados com onze tratamentos (arranjos espaciais) e cinco repetições, com parcelas subdivididas no tempo $(18,27,38$ e 51 meses após o plantio). Constatou-se que o volume de madeira por planta não mostrou diferença entre os distintos arranjos até 18 meses, sendo maior nos arranjos mais amplos a partir dos 27 meses. A partir de 38 meses, quanto maior a área útil por árvore, maior o diâmetro à altura do peito. Até quatro anos, os arranjos $3,33 \mathrm{~m} \times 2 \mathrm{~m} ; 3,33 \mathrm{~m} \times 3 \mathrm{~m}$ e $5 \mathrm{~m} \times 2 \mathrm{~m}$ são indicados para maior produção de madeira em termos quantitativos e os arranjos $10 \mathrm{~m} \times 3 \mathrm{~m} \mathrm{e} 10 \mathrm{~m}$ x $4 \mathrm{~m}$, para produção de madeira com maiores dimensões.
\end{abstract}

Termos para indexação: Eucalyptus, espaçamento, crescimento, silvipastoril, sistema agroflorestal.

\section{Silvicultural and Productive Performances of Eucalypt under Different Spatial Arrangements in Agrosilvipastoral System}

\begin{abstract}
Eucalypt wood production is associated with a long cutting cycle, wide spacing and specific silvicultural treatments, and allows intercropping with grain and forage producing species. The objective of this study was to evaluate the silvicultural and productive performances of eucalypt under different arrangements in agrosilvipastoral system. Clonally propagated E. camaldulensis x E. urophylla hybrid was planted in the Brazilian savanna. The plants were intercropped with rice (first year of planting), soybean (second year) and Brachiaria brizantha pasture (following years). The experimental design was randomized blocks with 11 treatments (11 arrangements of eucalypt) and five replications, with plots splitted along of the time (18, 27, 38 and 51 months after planting). There was no treatment effect in wood volume of eucalypt trees until 18 months after planting. Wood volume was greater in the larger spacings 27 months after planting. From month 38 on, diameter at breast height showed to be positively affected by the available area to each tree. Until the fourth year, the arrangements $3.33 \mathrm{mx} 2 \mathrm{~m}, 3.33 \mathrm{~m} \mathrm{x} 3 \mathrm{~m}$ and $5 \mathrm{mx} 2 \mathrm{~m}$ are indicated to quantity production wood, while $10 \mathrm{~m} \times 3 \mathrm{~m}$ e $10 \mathrm{~m} \times 4 \mathrm{~m}$ are indicated to produce major size wood.
\end{abstract}

Index terms: Eucalyptus, spacing, growth, silvipastoral, agroforestry system.

\section{Introdução}

Ademanda por madeira e derivados cresce anualmente, assim como por alimentos e outros produtos. Contudo, a exploração inadequada dos recursos naturais tem gerado degradação ambiental, desflorestamento e limitações no potencial produtivo de extensas áreas de ação antrópica. Atenção especial é dispensada à reposição da vegetação em áreas antropizadas, recuperação de matas ciliares e atividades de reflorestamento, com o objetivo de recuperar estas áreas e eliminar o déficit de madeira no Brasil.

Este fato pode estimular o aumento do número de empreendimentos voltados para o setor florestal. Em 2000, a área plantada com eucaliptos no Brasil foi estimada em aproximadamente 3 milhões de hectares. As florestas plantadas forneciam toda matéria-prima utilizada na produção de celulose, papel, aglomerados, 
chapas de fibra e MDF, além de $75 \%$ do carvão produzido no Brasil. Para produtos com maior valor agregado (madeira serrada, entre outros), a maior quantidade de madeira originava-se das florestas nativas, e os volumes fornecidos para produção de lenha industrial, lâminas e compensados, por florestas nativas e plantadas eram praticamente equivalentes (SOCIEDADE BRASILEIRA DE SILVICULTURA, 2005).

Embora seja conhecida na indústria de celulose, papel e carvão há bastante tempo, só recentemente a madeira do eucalipto está sendo empregada na obtenção de produtos com maior valor agregado. Há alguns anos, apresenta-se como alternativa de matéria-prima básica para diversos usos, principalmente na indústria moveleira (SILVA, 2002).

A produção de madeira para serraria, contudo, está condicionada a um ciclo de corte mais longo, exigindo tratos silviculturais específicos e espaçamentos mais amplos e, muitas vezes, rearranjos espaciais no povoamento, o que exige alterações nos padrões de manejo da maioria das florestas de eucalipto plantadas na atualidade.

Bernardo (1995) afirma que a definição de espaçamentos adequados para o estabelecimento de espécies florestais é especialmente importante para regiões onde os solos apresentam baixa fertilidade e a disponibilidade hídrica é relativamente baixa e irregular, assim como na região do cerrado. Segundo o autor, nesta condição de recursos escassos, o espaçamento torna-se muito relevante, visto que os mais fechados podem gerar intensa competição, enquanto espaçamentos mais abertos podem resultar em subutilização e menor produtividade das florestas.

Algumas empresas reflorestadoras, em atividade no cerrado, estão empenhadas no desenvolvimento de técnicas que visam aumentar a produtividade dos plantios, sendo contemplados estudos sobre novos espaçamentos, dentre outros aspectos (ASSIS et al., 1999).

O emprego de espaçamentos mais amplos permite o consórcio com espécies agrícolas e/ou pastagem, o que sugere a inserção do eucalipto em sistemas agrossilvipastoris sequenciais (BEZERRA, 1997; DUBÉ, 1999; OLIVEIRA, 2005; MACEDO et al., 2008; HIGASHIKAWA et al., 2009), procedimento que pode agregar bastante valor ao sistema pelo aproveitamento das entrelinhas para produção agrícola e pecuária, especialmente em áreas de cerrado com aptidão para estes tipos de uso da terra, bem como pela possível produção de madeira de maior calibre e, consequentemente, maior valor comercial.

Implantar sistemas agrossilvipastoris com eucalipto em região de cerrado, segundo Oliveira et al. (2000), é uma opção viável economicamente, desde que, no mínimo, $5 \%$ da madeira produzida seja utilizada para serraria, e o restante para energia ou outro fim com valor de mercado equivalente ou superior.

O desenvolvimento dos clones de eucalipto consorciados com milho, após o consórcio com arroz e soja, é considerado satisfatório, em termos de sobrevivência, altura de plantas, diâmetro à altura do peito, volume/árvore, volume/ha e forma retilínea do fuste (MACEDO et al., 2006).

Dubé (1999), Oliveira et al. (2000) e Souza et al. (2007) estudaram o aspecto econômico dos sistemas agrossilvipastoris e consideraram que, apesar da baixa produtividade das lavouras entre as linhas de eucalipto (20,16 sacos de arroz e 21,60 sacos de soja por hectare), elas permitem reduzir os custos de plantio das árvores e preparam o solo para a introdução das forrageiras melhoradas (braquiárias, tanzânia e mombaça), que formarão o sistema silvipastoril com eucalipto nas fases posteriores.

Poucos estudos foram desenvolvidos em sistemas agrossilvipastoris, visando avaliar o eucalipto em condições de plantio mais elaboradas (por exemplo em linhas simples ou duplas, sob adensamento moderado), uma vez que a maioria dos estudos concluídos aborda espaçamentos em torno de dois ou três metros entre plantas e entre linhas e em arranjos simplificados. Botelho (1998) cita que variações no modo de distribuição das plantas, mantendo-se a mesma densidade, podem afetar seu crescimento e a produtividade.

O objetivo deste trabalho foi avaliar e caracterizar a dinâmica de crescimento e produtividade de eucalipto sob diferentes arranjos espaciais de sistema agrossilvipastoril em área de cerrado de Minas Gerais, em quatro épocas, até 51 meses de idade.

\section{Material e Métodos}

A unidade experimental foi instalada em área de cerrado, no noroeste de Minas Gerais, Município de Paracatu, situada a $17^{\circ} 36^{\prime}$ de latitude Sul e $46^{\circ} 42^{\prime}$ de longitude Oeste, com altitude de $550 \mathrm{~m}$. 
O clima da região é tropical úmido de savana, tipo Aw, com inverno seco e verão chuvoso, conforme a classificação de Köppen. A temperatura média anual é de $22,6^{\circ} \mathrm{C}$ e a precipitação média anual é de $1.450 \mathrm{~mm}$, concentrada, principalmente, nos meses de novembro a fevereiro (ANTUNES, 1986; BRASIL, 1992). O solo predominante na área é do tipo Latossolo Vermelho Amarelo distrófico.

O experimento foi instalado no mês de dezembro, no início do período chuvoso, sob a forma de um sistema agrossilvipastoril sequencial. Sendo disposto em uma área plana, o preparo e a correção do solo consistiram de uma aração profunda e duas gradagens niveladoras mais aplicação de 2,5 t/ha de calcário zincal MMA (85\% PRNT) entre três e dois meses antes do plantio das mudas. Utilizando-se grade tipo bedding, foram levantados camalhões com altura aproximada de $40 \mathrm{~cm}$, para plantio de mudas clonais de um híbrido natural de Eucalyptus camaldulensis Dehnh com Eucalyptus urophylla S.T. Blake, selecionado para produção de madeira para serraria.

A dinâmica de implantação e manejo do sistema agrossilvipastoril foi descrita por Macedo et al. (2000). No ano zero, marco inicial das atividades, promoveu-se a abertura do cerrado e plantio das mudas de eucalipto. Ainda naquele ano, nas entrelinhas de eucalipto, foram plantadas variedades de arroz (Oriza sativa L.). No ano dois, as entrelinhas de eucalipto foram cultivadas com soja (Glycine max (L.) Merrill), e posterior a formação de pastagem de Brachiaria brizantha (Hochst. ex A. Rich.) Stapf cv. Marandu no sub-bosque do eucalipto. A partir do ano 3, permitiu-se a introdução de bovinos no sistema, embora o presente estudo tenha sido desenvolvido em período anterior ao primeiro pastejo pelos animais.

O plantio do arroz e da soja foi realizado respeitandose $1 \mathrm{~m}$ de espaço livre, de cada lado da linha de plantio do eucalipto. A braquiária foi semeada a lanço em toda a área do sub-bosque do povoamento florestal.

Ao longo dos anos de plantio, após a instalação do experimento, foram realizados os tratos culturais e silviculturais necessários para cada cultura, respeitandose as respectivas recomendações técnicas sobre seu cultivo convencional no cerrado.

O delineamento utilizado foi o de blocos casualizados, em esquema de parcelas subdivididas no tempo, com cinco repetições. Nas parcelas, estudou-se o efeito de onze arranjos espaciais do componente florestal
(Figura 1): 3,33 m x $2 \mathrm{~m} ; 3,33 \mathrm{~m} \mathrm{x} 3 \mathrm{~m} ; 5 \mathrm{~m} \mathrm{x} 2 \mathrm{~m}$; $10 \mathrm{~m} \times 2 \mathrm{~m} ; 10 \mathrm{~m} \times 3 \mathrm{~m} ; 10 \mathrm{~m} \times 4 \mathrm{~m} ;(3 \mathrm{~m} \times 4 \mathrm{~m})+7 \mathrm{~m} ;(3 \mathrm{~m}$ x $3 m)+10 m ;(3 m \times 4 m)+10 m ;(3 m \times 3 m)+15 m$ e $(3 m x$ $4 \mathrm{~m})+7+10 \mathrm{~m}$. As parcelas experimentais permanentes foram implantadas com uma planta em cada bordadura de cabeceira e duas linhas em cada bordadura lateral.

Os tratamentos das subparcelas corresponderam às quatro épocas de avaliação $(18,27,38$ e 51 meses após o plantio). Para os arranjos mais adensados $(3,33 \mathrm{~m} \mathrm{x}$ $2 \mathrm{~m} ; 3,33 \mathrm{~m} \times 3 \mathrm{~m}$ e $5 \mathrm{~m} \times 2 \mathrm{~m}$ ) não houve consórcio com as culturas agrícolas e pastagem, em função da impossibilidade de mecanização das entrelinhas utilizando o equipamento disponível.

Após 18, 27, 38 e 51 meses do plantio do eucalipto, foram coletados dados das variáveis diâmetro à altura do peito (DAP) e altura total da planta (H). Destes valores, foram calculados a área basal por planta e por hectare, o volume por planta (utilizando o fator de forma igual a $0,4)$, o volume por hectare e o incremento médio anual do volume por hectare. $\mathrm{O}$ incremento corrente anual do volume por hectare foi calculado para as três últimas épocas de avaliação.

Os dados obtidos foram submetidos à análise de variância e foi aplicado o teste de Scott e Knott (1974) $(\mathrm{P}<0,05)$ às médias dos onze arranjos espaciais em cada época de avaliação. Para realização das análises, utilizou-se o programa estatístico SISVAR (FERREIRA, 2000).

\section{Resultados e Discussão}

Verificou-se que houve interação significativa entre os arranjos espaciais e as épocas de avaliação para todas as variáveis analisadas, exceto para volume por planta (Tabela 1). Aos 18 meses após o plantio, os menores valores em DAP e área basal foram observados para os arranjos $3,33 \mathrm{~m} \times 2 \mathrm{~m} ;(3 \mathrm{~m} \times 4 \mathrm{~m})+7 \mathrm{~m} ;(3 \mathrm{~m} \times 3 \mathrm{~m})+10 \mathrm{~m}$ e $(3 \mathrm{~m} \mathrm{x} 4 \mathrm{~m})+10 \mathrm{~m}$.

A altura de plantas foi maior nos arranjos mais adensados (3,33 m x $2 \mathrm{~m} ; 3,33 \mathrm{~m}$ x $3 \mathrm{~m}$ e $5 \mathrm{~m} \times 2 \mathrm{~m})$. $\mathrm{O}$ maior crescimento inicial em altura das plantas nos espaçamentos menores confirma as constatações de Patiño-Valera (1986), Bernardo (1995) e Assis et al. (1999).

A área basal/ha foi superior nos arranjos mais adensados, em função do número de árvores/ha ser maior nestes tratamentos. 


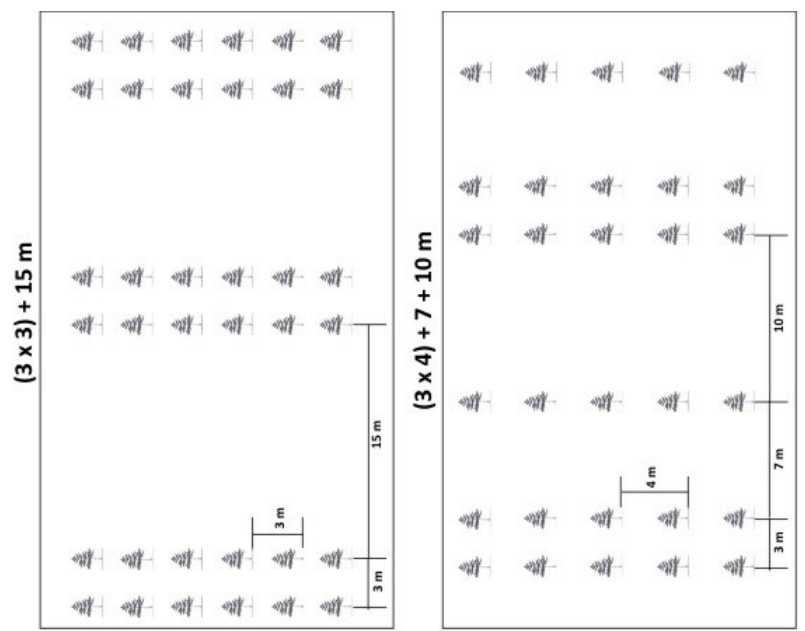



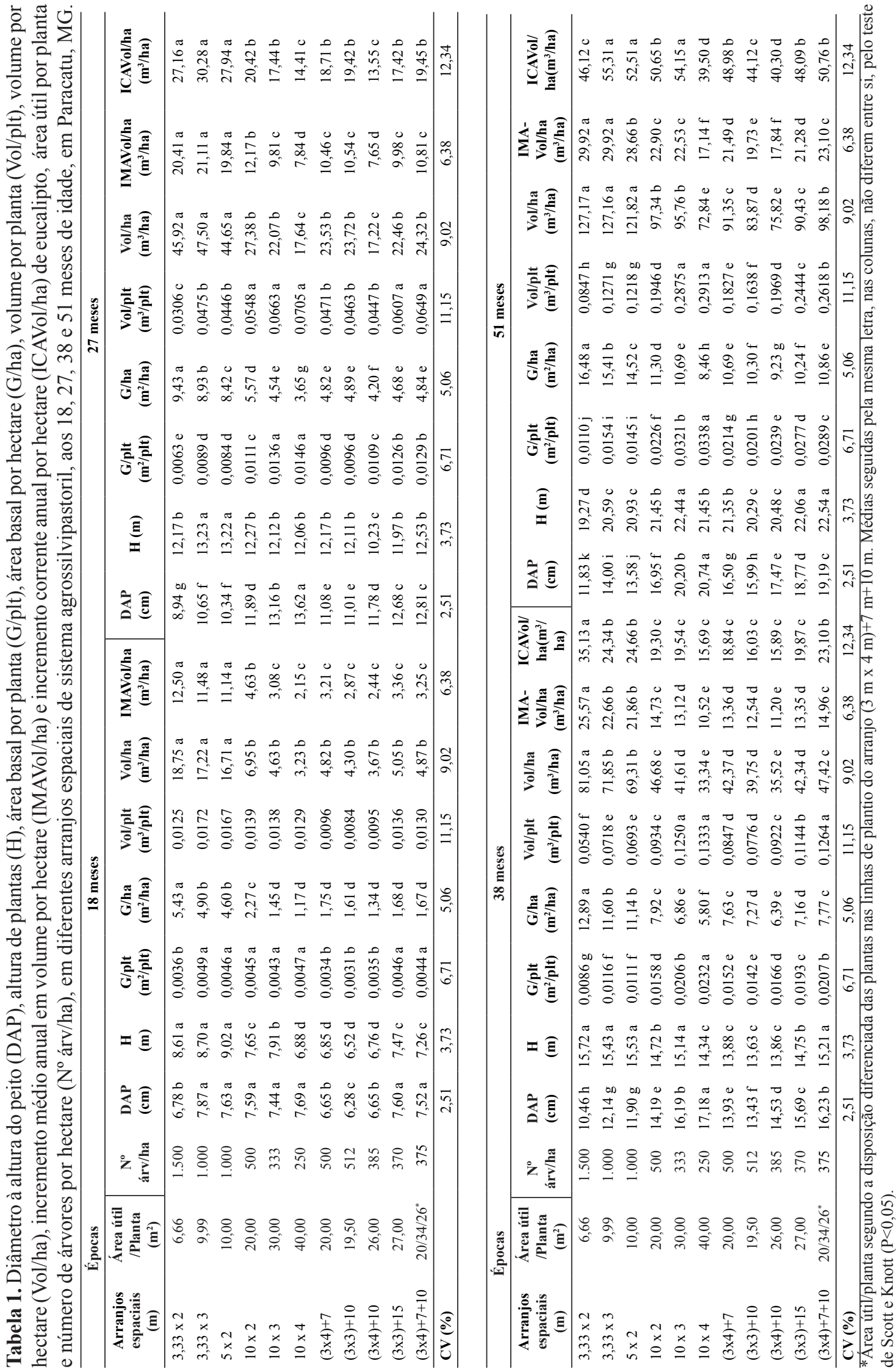
Aos 18 meses após o plantio, os arranjos espaciais não influenciaram o desempenho produtivo das plantas individualmente, considerando que não houve diferença significativa no volume/planta. Contudo, assim como para área basal/ha, o incremento médio anual em volume por hectare (IMAVol/ha) e o volume/ha foram influenciados pelo número de árvores, de maneira que, para os arranjos mais adensados $(3,33 \mathrm{~m} \times 2 \mathrm{~m} ; 3,33 \mathrm{~m} \times 3 \mathrm{~m}$ $\mathrm{e} 5 \mathrm{mx} 2 \mathrm{~m}$ ), foram encontradas as maiores produtividades em volume, de $16,71 \mathrm{~m}^{3} / \mathrm{ha}$ a $18,75 \mathrm{~m}^{3} /$ ha, comparadas a um intervalo de $3,23 \mathrm{~m}^{3} / \mathrm{ha}$ a $6,95 \mathrm{~m}^{3} /$ ha para os demais tratamentos. Botelho (1998) e Oliveira Neto et al. (2003) citam que ocorre maior produção por unidade de área nos espaçamentos mais reduzidos em função do maior número de indivíduos. Os arranjos mais adensados apresentaram os maiores incrementos, da ordem de 11,14 a $12,5 \mathrm{~m}^{3} /$ ha ano.

Aos 27 meses após o plantio, verificaram-se maiores DAPs nas plantas cultivadas no arranjo $10 \mathrm{~m} \mathrm{x} 4 \mathrm{~m}$ e $10 \mathrm{~m} \times 3 \mathrm{~m}$, menores nos arranjos mais adensados, e intermediários para os demais, demonstrando a influência da área útil por planta no crescimento em diâmetro do eucalipto por volta de dois anos de idade. Estes resultados corroboram com os de Bernardo (1995) e Oliveira Neto et al. (2003), os quais mostraram que esse efeito se expressa logo na fase inicial de desenvolvimento das plantas.

A altura de plantas foi superior nos arranjos 3,33 $\mathrm{m} \mathrm{x}$ $2 \mathrm{~m}$ e $5 \mathrm{~m} \times 2 \mathrm{~m}$ e menor no $(3 \mathrm{~m} \times 4 \mathrm{~m})+10 \mathrm{~m}$.

A área basal por hectare foi superior nos arranjos $3,33 \mathrm{~m} \times 2 \mathrm{~m} ; 3,33 \mathrm{~m} \times 3 \mathrm{~m}$ e $5 \mathrm{~m} \times 2 \mathrm{~m}$, nesta ordem, especialmente em consequência do maior número de árvores por unidade de área nestes tratamentos.

Quanto ao volume por planta, tornou-se evidente, aos 27 meses, o efeito positivo dos arranjos com maior área útil por planta, $10 \mathrm{~m} \times 4 \mathrm{~m} ; 10 \mathrm{~m}$ x $3 \mathrm{~m} ; 10 \mathrm{~m}$ x $2 \mathrm{~m}$; (3 m x $3 \mathrm{~m})+15 \mathrm{~m}$ e $(3 \mathrm{~m} \times 4 \mathrm{~m})+7 \mathrm{~m}+10 \mathrm{~m}$.

Deve-se destacar que o comportamento das árvores com relação ao volume por planta é definido em função do arranjo, considerando que, no plantio em linhas simples $10 \mathrm{~m} \times 2 \mathrm{~m}$, as plantas apresentaram maior volume que nas linhas duplas $(3 \mathrm{~m} \mathrm{x} 4 \mathrm{~m})+7 \mathrm{~m}$ e $(3 \mathrm{~m}$ x $3 \mathrm{~m})+10 \mathrm{~m}$, mesmo com cerca de $20 \mathrm{~m}^{2}$ de área útil por planta, comum para estes tratamentos.

Os maiores valores para volume por hectare, IMAVol/ ha e ICAVol/ha foram encontrados para os arranjos mais adensados. Mesmo sendo destes o pior desempenho em volume por planta, o efeito do número de plantas por unidade de área foi fundamental na determinação da produtividade em volume/ha, confirmando as conclusões de Pinkard e Neilsen (2003).

Pode-se verificar, pelos dados de ICAVol/ha, que a floresta produziu aproximadamente de $27 \mathrm{~m}^{3} /$ ha a $30 \mathrm{~m}^{3} /$ ha nos arranjos $3,33 \mathrm{~m} \mathrm{x} 2 \mathrm{~m} ; 3,33 \mathrm{~m} \mathrm{x}$ $3 \mathrm{~m}$ e $5 \mathrm{~m} \times 2 \mathrm{~m}$, do primeiro para o segundo ano, enquanto que, para os demais tratamentos, variou de $13,5 \mathrm{~m}^{3} /$ ha a $20,5 \mathrm{~m}^{3} / \mathrm{ha}$.

Aos 38 meses após o plantio, constata-se que o DAP foi superior nos arranjos em que havia maior área útil por planta. Ao redor dos três anos de idade, estabeleceu-se um gradiente para o crescimento em diâmetro segundo o espaço disponível, nesta ordem decrescente: $10 \mathrm{~m} \mathrm{x}$ $4 \mathrm{~m}\left(40 \mathrm{~m}^{2}\right) ;(3 \mathrm{~m} \mathrm{x} 4 \mathrm{~m})+7 \mathrm{~m}+10 \mathrm{~m}\left(26,7 \mathrm{~m}^{2}\right) ; 10 \mathrm{~m}$

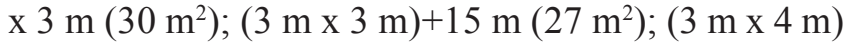
$+10 \mathrm{~m}\left(26 \mathrm{~m}^{2}\right) ; 10 \mathrm{~m} \times 2 \mathrm{~m},(3 \mathrm{~m} \mathrm{x} 4 \mathrm{~m})+7 \mathrm{~m} \mathrm{e}(3 \mathrm{~m} \mathrm{x}$ $3 \mathrm{~m})+10 \mathrm{~m}$ (arranjos com área útil em torno de $20 \mathrm{~m}^{2}$ ); $3,33 \mathrm{~m} \times 3 \mathrm{~m}$ e $5 \mathrm{~m} \times 2 \mathrm{~m}$ (área útil comum de $10 \mathrm{~m}^{2}$ ) e $3,33 \mathrm{~m} \times 2 \mathrm{~m}\left(6,7 \mathrm{~m}^{2}\right)$.

$\mathrm{O}$ comportamento das plantas quanto à altura não reflete o crescimento em diâmetro. Para altura, aos três anos de idade, os melhores arranjos foram os mais adensados, seguidos do $(3 \mathrm{~m} \mathrm{x} 4 \mathrm{~m})+7 \mathrm{~m}+10 \mathrm{~m}$ e do $10 \mathrm{~m}$ x $3 \mathrm{~m}$. Bernardo (1995) cita que, de modo geral, o crescimento em diâmetro é uma característica altamente responsiva aos espaçamentos. Contudo, existe certa controvérsia quanto aos reflexos sobre a altura das árvores na fase jovem do crescimento, havendo casos em que ocorre aumento da altura em espaçamentos maiores e outros em que o resultado é o oposto.

As variáveis G/plt e Vol/plt, sendo altamente influenciadas pelo DAP, foram maiores nos arranjos $10 \mathrm{~m} \times 4 \mathrm{~m} ; 10 \mathrm{~m} \times 3 \mathrm{~m}$; $(3 \mathrm{~m} \times 3 \mathrm{~m})+15 \mathrm{~m}$ e $(3 \mathrm{~m} \times 4 \mathrm{~m})+7 \mathrm{~m}+10 \mathrm{~m}$, dos quais a maior área útil por planta proporcionou os maiores valores para esta variável, aos três anos. Estes resultados estão de acordo com Pinkard e Neilsen (2003), que encontraram maior volume por árvore devido ao maior DAP, em povoamento com 500 árvores de Eucalyptus nitens por hectare, comparado com densidades de até 1.667 árvores por hectare.

Assim como nas avaliações anteriores, a $\mathrm{G} / \mathrm{ha}$ e o Vol/ha foram superiores nos arranjos mais adensados, de acordo com o maior número de árvores por área.

Em função dos resultados de Vol/ha, os maiores IMAVol/ha $\left(21,86-25,57 \mathrm{~m}^{3} / \mathrm{ha}\right)$ e ICAVol/ha $(24,34-$ $35,13 \mathrm{~m}^{3} / \mathrm{ha}$ ), com pouco mais de três anos de idade, 
também foram superiores nos arranjos mais adensados.

Aos 51 meses de idade, constatou-se novamente a influência positiva da área útil por planta, expressa pelos diferentes arranjos, no crescimento em diâmetro. As árvores alcançaram maiores valores, mais de $20 \mathrm{~cm}$ de DAP, no arranjo $10 \mathrm{~m} \mathrm{x} 4 \mathrm{~m}$, seguido do $10 \mathrm{~m} \times 3 \mathrm{~m}$, acentuando-se mais o gradiente de aumento do crescimento em diâmetro conforme o aumento da área útil por planta, em função do arranjo estrutural. Comportamento semelhante foi verificado por Leite et al. (1997), avaliando diferentes densidades populacionais de eucalipto, de 500 a 5 mil plantas por hectare.

O menor valor encontrado para DAP, aos 27 meses, em plantas do arranjo $3,33 \mathrm{~m} \times 2 \mathrm{~m}$ foi equivalente a $65,6 \%$ do DAP médio de plantas no arranjo $10 \mathrm{~m} \mathrm{x} 4 \mathrm{~m}$, que apresentaram o maior valor. Esta porcentagem caiu para $60,9 \%$ aos 38 meses e $57 \%$ aos 51 meses. Isto mostra que a taxa de crescimento em DAP diminui ao longo do tempo nos espaçamentos reduzidos. Resultado semelhante foi verificado por Leite et al. (1997).

As maiores alturas foram as dos arranjos $10 \mathrm{~m} \mathrm{x} 3 \mathrm{~m}$; $(3 \mathrm{~m} \times 3 \mathrm{~m})+15 \mathrm{~m}$ e $(3 \mathrm{~m} \times 4 \mathrm{~m})+7 \mathrm{~m}+10 \mathrm{~m}$, nos quais as árvores atingiram mais de $22 \mathrm{~m}$ de altura total aos quatro anos. Apesar da maior altura nos espaçamentos mais densos até três anos, Bernardo (1995) cita que ocorre diminuição nos valores de altura média das árvores com o passar do tempo, à medida que se diminui o espaçamento, em razão do aumento do número de árvores dominadas.

Pode-se inferir, ainda, que a maior altura em alguns dos espaçamentos mais amplos, aos quatro anos, deva-se ao efeito da competição por água e nutrientes nos arranjos com menor área útil, com consequente diminuição da taxa de crescimento. Leite et al. (1997) constataram que, em períodos com menos água disponível no solo, houve maior restrição ao crescimento onde as plantas estavam mais adensadas. Resultados semelhantes foram encontrados por Leles et al. (1998), para $E$. camaldulensis, aos 52 meses de idade, em espaçamentos variando de $3 \mathrm{~m} \times 1 \mathrm{~m}$ a $9 \mathrm{~m} \mathrm{x} 9 \mathrm{~m}$.

Silva (1999) citou que as relações hídricas para $E$. grandis demonstraram que plantas estabelecidas nos espaçamentos mais amplos apresentaram um melhor status hídrico, e o consórcio, nestas condições, não prejudica a espécie arbórea devido aos sistemas radiculares das plantas do consórcio explorarem horizontes diferentes do solo.
Os valores encontrados para altura de plantas variaram de $19,27 \mathrm{~m}$ a 22,44 m. Entretanto, o DAP foi definitivo na expressão das variáveis $\mathrm{G} / \mathrm{plt}$ e Vol/plt, em virtude da diferenciação estatística bastante semelhante entre os mesmos arranjos para essas três variáveis. Os maiores G/plt e Vol/plt foram dos arranjos $10 \mathrm{~m}$ x $4 \mathrm{~m}$ e $10 \mathrm{~m}$ x $3 \mathrm{~m}$. Os maiores valores para área basal por hectare variaram de $14,52 \mathrm{~m}^{2} /$ ha a $16,48 \mathrm{~m}^{2} /$ ha. E para volume, de $121,82 \mathrm{~m}^{2} /$ ha a $127,17 \mathrm{~m}^{3} / \mathrm{ha}$, nos arranjos $5 \mathrm{~m} \mathrm{x} 2 \mathrm{~m}$; $3,33 \mathrm{~m} \times 3 \mathrm{~m}$ e $3,33 \mathrm{~m} \times 2 \mathrm{~m}$.

O maior crescimento e produtividade individual, observados em plantas com maior área útil, não compensaram a produção obtida pelo maior número de árvores nos arranjos com espaçamentos menores, até os quatro anos de idade.

À exceção do $(3 \mathrm{~m}$ x $4 \mathrm{~m})+10 \mathrm{~m}$, vale ressaltar que os demais arranjos apresentaram, aos quatro anos, resultados superiores, com diferença significativa para Vol/ha em relação ao $10 \mathrm{~m} \mathrm{x} 4 \mathrm{~m}$, que é o espaçamento padrão utilizado na maioria dos sistemas agrossilvipastoris implantados em área contínua, na região de cerrado do presente estudo. Contudo, em virtude da idade relativamente jovem do povoamento, este fato pode não indicar a mesma tendência de comportamento em idades mais avançadas, considerando-se especialmente a quantidade de recursos disponíveis na maior área útil para as plantas cultivadas nos arranjos mais amplos.

A produtividade aos quatro anos foi de $72,84 \mathrm{~m}^{3} / \mathrm{ha}$ nas parcelas estabelecidas no arranjo $10 \mathrm{~m} \mathrm{x} 4 \mathrm{~m}$, e acima de $90 \mathrm{~m}^{3} /$ ha nos arranjos $10 \mathrm{~m} \times 2 \mathrm{~m} ; 10 \mathrm{~m} \times 3 \mathrm{~m}$; ( $3 \mathrm{~m} \mathrm{x}$ $4 \mathrm{~m})+7 \mathrm{~m} ;(3 \mathrm{~m} \times 3 \mathrm{~m})+15 \mathrm{~m}$ e $(3 \mathrm{~m} \times 4 \mathrm{~m})+7 \mathrm{~m}+10 \mathrm{~m}$. De acordo com o crescimento do povoamento florestal, pode-se predizer que irão se destacar no futuro aqueles arranjos com maior área útil por planta, com grande possibilidade de ainda existir efeito do arranjo sobre o desempenho silvicultural das árvores e do sistema como um todo.

Arranjos com maior área útil e espaçamentos mais amplos nas entrelinhas, com razoável número de árvores por hectare e com a finalidade de produzir madeira para serraria [10 m x $4 \mathrm{~m} ; 10 \mathrm{~m} \times 3 \mathrm{~m}$ e $(3 \mathrm{~m} \times 3 \mathrm{~m})+15 \mathrm{~m}]$, apresentam ainda a vantagem de permitir consórcio com culturas agrícolas por maior período, possivelmente contando com menores limitações em termos de competição por espaço, luz, água e nutrientes.

A média de produção anual em volume de madeira em quatro anos foi superior a $28 \mathrm{~m}^{3} /$ ha ano nos arranjos mais adensados, expressos pelo IMAVol/ha. Esta 
produtividade confirma o que foi relatado por Novais et al. (1996), que citam a obtenção de $25 \mathrm{~m}^{3}$ a $30 \mathrm{~m}^{3}$ de madeira/ha.ano, por meio de correção e fertilização adequada nos solos de cerrado, associada à utilização de espécies/genótipos adaptados ao local.

Aos 51 meses, destacou-se com maior crescimento e acúmulo de madeira do terceiro para o quarto ano o arranjo 3,33 m x $3 \mathrm{~m}$, que foi estatisticamente igual ao $10 \mathrm{~m} \times 3 \mathrm{~m}$ e $5 \mathrm{~m} \times 2 \mathrm{~m}$ (ICAVol/ha médio para estes três arranjos em torno de $\left.54 \mathrm{~m}^{3} / \mathrm{ha}\right)$. Estes arranjos, juntamente com o $10 \mathrm{~m}$ x $2 \mathrm{~m}$; (3 m x $4 \mathrm{~m})+7 \mathrm{~m}$; (3 m x $3 \mathrm{~m})+15 \mathrm{me}(3 \mathrm{mx} 4 \mathrm{~m})+7 \mathrm{~m}+10 \mathrm{~m}$, foram estatisticamente superiores ao $3,33 \mathrm{~m} \times 2 \mathrm{~m}$, que apresentou os maiores ICAVol/ha nas avaliações anteriores. Com relação à produção de madeira, isto indica superação do fator densidade de plantio nos arranjos mais amplos em relação aos mais densos com o passar do tempo. Apesar do maior número de árvores/ha no 3,33 m x 2 m, tal fato sugere uma compensação por meio do maior acúmulo de madeira nos demais tratamentos, do terceiro para o quarto ano de idade.

O máximo ICA, segundo Botelho (1998), ocorre mais cedo em povoamentos menos espaçados, apresentando altos valores na fase inicial e um decréscimo acentuado após o máximo ICA. Enquanto o ICAVol/ha para o $3,33 \mathrm{~m} \times 2 \mathrm{~m}$ foi de $35,13 \mathrm{~m}^{3} /$ ha para $46,12 \mathrm{~m}^{3} /$ ha do terceiro para o quarto ano, todos os demais arranjos produziram, no quarto ano, mais que o dobro de madeira do ano anterior (Tabela 1). Este resultado denota a ocorrência de competição precoce em espaçamentos menores.

Considerando o incremento corrente anual, apesar de alguns arranjos com maior área por planta apresentaremse quantitativamente em desvantagem em relação aos demais, a princípio, foram progressivamente melhorando seu desempenho, com tendência, após 51 meses do plantio, de se igualarem aos que lhes eram inicialmente superiores.

A equivalência em produção entre os povoamentos florestais nos diferentes arranjos, com o passar do tempo, indica a possibilidade dos arranjos com espaços maiores superarem o volume por hectare de plantios mais adensados. Soma-se a este fato a vantagem da produção de madeira para serraria, com finalidades economicamente mais atrativas, haja vista as dimensões do fuste e da árvore, que atingiram, neste estudo, valores acima de $20 \mathrm{~cm}$ de DAP aos quatro anos, nos arranjos $10 \mathrm{~m} \times 3 \mathrm{~m}$ e $10 \mathrm{~m}$ x $4 \mathrm{~m}$, superando os DAPs de 11,83 $\mathrm{cm}$ a $14 \mathrm{~cm}$ nos arranjos $3,33 \mathrm{~m}$ x $2 \mathrm{~m} ; 3,33 \mathrm{~m}$ x $3 \mathrm{~m}$ e $5 \mathrm{~m} \mathrm{x}$ $2 \mathrm{~m}$, na mesma idade.

Sugere-se continuidade nas avaliações com o objetivo de verificar esta possibilidade, bem como para gerar informações sobre microclima, produtividade dos animais componentes do sistema, fertilidade do solo e condução da forrageira no sub-bosque, fornecendo recomendações técnicas confiáveis a respeito da implantação e manejo de sistemas agrossilvipastoris com eucalipto.

\section{Conclusões}

Árvores com mesma área útil apresentam crescimento diferenciado em linhas simples quando comparado a linhas duplas.

A partir do terceiro ano se estabelece um gradiente de valores para diâmetro à altura do peito (DAP), de acordo com a área útil disponível; quanto maior a área útil maior o DAP.

A taxa de crescimento diminui nos arranjos com espaçamentos mais reduzidos, ao longo do tempo. E o aumento da área útil por árvore propicia maiores volumes individuais.

Até quatro anos, os arranjos $3,33 \mathrm{~m} \times 2 \mathrm{~m} ; 3,33 \mathrm{~m} \times 3 \mathrm{~m} \mathrm{e}$ $5 \mathrm{~m} \times 2 \mathrm{~m}$ são mais indicados para maior produção de madeira em termos quantitativos. Enquanto os arranjos $10 \mathrm{~m} \times 3 \mathrm{~m}$ e 10 m x 4 m são indicados para produção de madeira com maiores dimensões.

\section{Agradecimentos}

Agradecemos à Companhia Mineira de Metais (CMM Agroflorestal), pela oportunidade de execução da pesquisa e pelo apoio incondicional na implantação e avaliação dos experimentos. Em especial ao diretor Vicente de Paula Silveira e aos técnicos Carlos Coelho e Celso Machado.

\section{Referências}

ANTUNES, F. Z. Caracterização climática do Estado de Minas Gerais: climatologia agrícola. Informe agropecuário, Belo Horizonte, v. 12, n. 138, p. 9-13, jun. 1986.

ASSIS, R. L. de; FERREIRA, M. M.; MORAIS, E. J. de; FERNANDES, L. A. Produção de biomassa de Eucalyptus urophylla $\mathrm{S}$. T. Blake sob diferentes espaçamentos na região de cerrado de Minas Gerais. Revista Árvore, Viçosa, v. 23, n. 2, p. 151-156, abr./jun. 1999. 
BERNARDO, A. L. Crescimento e eficiência nutricional de Eucalyptus spp. Sob diferentes espaçamentos na região do cerrado de Minas Gerais. 1995. 102 p. Dissertação (Mestrado em Ciências Florestais) - Universidade Federal de Viçosa, Viçosa, MG.

BEZERRA, R. G. Consórcios de clones de eucalipto com soja e milho na região de cerrado no noroeste do Estado de Minas Gerais: um estudo de caso. 1997. 91 p. Dissertação (Mestrado em Engenharia Florestal) - Universidade Federal de Lavras, Lavras, MG.

BOTELHO, S. A. Espaçamento. In: SCOLFORO, J. R. S. Manejo florestal. Lavras: UFLA/FAEPE, 1998. p. 381-405.

BRASIL. Ministério da Agricultura e Reforma Agrária. Departamento Nacional de Meteorologia. Normais climatológicas (1961-1990). Brasília: MARA, 1992. 84 p.

DUBÉ, F. Estudos técnicos e econômicos de sistemas agroflorestais com Eucalyptus sp. No Noroeste do Estado de Minas Gerais: o caso da Companhia Mineira de Metais. 1999. 146 p. (Dissertação - Mestrado em Ciência Florestal) Universidade Federal de Viçosa, Viçosa, MG.

FERREIRA, D. F. Análises estatísticas por meio do SISVAR (Sistema para Análise de Variância) para Windows versão 4.0. In: REUNIÃO ANUAL DA REGIÃO BRASILEIRA DA SOCIEDADE INTERNACIONAL DE BIOMETRIA, 45., 2000, São Carlos. Anais... São Carlos: FSCar: 2000. p. 255-258.

HIGASHIKAWA, E. M.; MACEDO, R. L. G.; VENTURIM, N.; COSTA, K. L.; MELIDO, R. C. N. Clones de Eucalyptus spp. em sistema agrossilvispastoril na região noroeste do Estado de Minas Gerais, Brasil. In: CONGRESSO BRASILEIRO DE SISTEMAS AGROFLORESTAIS, 7., 2009, Luziânia. Anais... Luziânia: Embrapa/MAPA/EMATER-DF/MULTIRÃO AGROFLORESTAL, 2009. (CD-ROM)

LEITE, F. P.; BARROS, N. F. de; NOVAIS, R. F. de; SANS, L. M. A.; FABRES, A. S. Crescimento de Eucalyptus grandis em diferentes densidades populacionais. Revista Árvore, Viçosa, v. 21, n. 3, p. 313-321, jul./set. 1997.

LELES, P. S. dos S.; REIS, G. G. dos; REIS, M. das G. F.; MORAIS, E. J. de. Relações hídricas e crescimento de árvores de Eucalyptus camaldulensis e Eucalyptus pellita sob diferentes espaçamentos na região de cerrado. Revista Árvore, Viçosa, v. 22, n. 1, p. 41-50, jan./mar. 1998.

MACEDO, R. L. G.; BEZERRA, R. G.; VENTURIN, N.; VALE, R. S. do; OLIVEIRA, T. K. de. Desempenho silvicultural de clones de eucalipto e características agronômicas de milho cultivados em sistema silviagrícola. Revista Árvore, Viçosa, v. 30, n. 5, p. 701-709, 2006.

MACEDO, R. L. G.; FURTADO, S. C.; OLIVEIRA, T. K. de; GOMES, J. E. Caracterização e manejo dos principais sistemas silvipastoris e agrossilvipastoris. In: MACEDO, R. L. G.

Princípios básicos para o manejo sustentável de sistemas agroflorestais. Lavras: UFLA/FAEPE, 2000. p. 90-137.
MACEDO, R. L. G; VALE, A. B. do; VENTURIN, N. Eucalipto em sistemas silvipastoris e agrossilvipastoris. Informe Agropecuário, EPAMIG, Belo Horizonte, v.29, n.242, p. 71-85, jan./fev. 2008.

NOVAIS, R. F. de; BARROS, N. F. de; COSTA, L. M. da. Aspectos nutricionais e ambientais do eucalipto. Silvicultura, São Paulo, n. 68, p. 10-17, set/out, 1996.

OLIVEIRA, A. D. de; SCOLFORO, J. R. S.; SILVEIRA, V. de P. Análise econômica de um sistema agro-silvo-pastoril com eucalipto implantado em região de cerrado. Ciência Florestal, Santa Maria, v. 10, n. 1, p. 1-19, jun. 2000.

OLIVEIRA NETO, S. N. de; REIS, G. G. dos; REIS, M. das G. F.; NEVES, J. C. L. Produção e distribuição de biomassa em Eucalyptus camalduelnsis Dehn. Em resposta à adubação e ao espaçamento. Revista Árvore, Viçosa, v. 27, n. 1, p. 15-23, jan./ fev. 2003.

OLIVEIRA, T. K. de. Sistema agrossilvipastoril com eucalipto e braquiária sob diferentes arranjos estruturais em área de Cerrado. 2005. 150 p. Tese (Doutorado), Universidade Federal de Lavras, Lavras.

PATIÑO-VALERA, F. Variação genética em progênies de Eucalyptus saligna Smith e sua interação com espaçamento. 1986. 192 p. Dissertação (Mestrado) - Escola Superior de Agricultura Luiz de Queiroz, Piracicaba.

PINKARD, E. A.; NEILSEN, W. A. Crown and stand characteristics of Eucalyptus nitens in response to initial spacing: implications for thinning. Forest Ecology and Management, Amsterdam, v. 172, n. 2/3, p. 215-227, Jan. 2003.

SCOTT, A. J.; KNOTT, M. A cluster analysis method for grouping means in the analysis of variance. Biometrics, Fort Collins, v.30, n. 3, p. 507-512, Sep. 1974.

SILVA, J. de C. Caracterização da madeira de Eucalyptus grandis Hill Ex. Maiden, de diferentes idades, visando a sua utilização na indústria movelveira. Revista Floresta, Curitiba, v. 32, n. 2, p. 322-323, jul./dez. 2002.

SILVA, J. M. S. da. Estudo silvicultural e econômico do consórcio de Eucalyptus grandis com gramíneas sob diferentes espaçamentos em áreas acidentadas. 1999. 115 p. Dissertação (Mestrado em Ciência Florestal) - Universidade Federal de Viçosa, Viçosa, MG.

SOCIEDADE BRASILEIRA DE SILVICULTURA. Estatísticas. Disponível em: $<$ http:/www.sbs.org.br/estatisticas.htm>. Acesso em: 21 jan. 2005.

SOUZA, A. N.; OLIVEIRA, A. D.; SCOLFORO, J. R. S.; REZENDE, J. L. P. de; MELLO, J. M. de. Viabilidade econômica de um sistema agroflorestal. CERNE, Lavras, v. 13, p. 96-106, 2007.

Recebido em 21 de maio de 2009 e aprovado em 12 de outubro de 2009 
